\title{
Theoretical Study of Wind Turbine Model with a New Concept on Swept Area
}

\author{
Sagarkumar M. Agravat ${ }^{*}$, N. V. S. Manyam², Sanket Mankar ${ }^{3}$, T. Harinarayana1 \\ ${ }^{1}$ Gujarat Energy Research and Management Institute, Gandhinagar, India \\ ${ }^{2}$ Department of Electrical Engineering, University of Petroleum and Energy Studies, Dehradun, India \\ ${ }^{3}$ School of Mechanical and Building Sciences, Vellore Institute of Technology, Vellore, India \\ Email: ${ }^{*}$ sagar.a@germi.res.in
}

Received 18 February 2015; accepted 5 April 2015; published 10 April 2015

Copyright (C) 2015 by authors and Scientific Research Publishing Inc.

This work is licensed under the Creative Commons Attribution International License (CC BY).

http://creativecommons.org/licenses/by/4.0/

(c) (i) Open Access

\begin{abstract}
Commercially available wind-turbines are optimized to operate at certain wind velocity, known as rated wind velocity. For other values of wind velocity, it has different output which is lower than the rated output of the wind plant. Wind mill can be designed to provide maximum power output at different wind velocities through modification of swept area to match with the wind speed available at the moment. This can result in higher power output at all the velocities except that at rated wind speed because of limitation of generator. This results in increased utilization of generation capacity of wind mill compared to its commercially designed counterpart. A theoretical simulation has been done to prove a new concept about swept area of wind turbine blade which results in a significant increase in the power output through the year. Simulation results of power extracted through normal wind blade design and new concept are studied and compared. The findings of the study are presented in graphical and tabular form. Study establishes that there can be a significant gain in the power output with the new concept.
\end{abstract}

\section{Keywords}

Cut-In Wind-Speed, Cut-Out Wind-Speed, CUF, Swept Area, Radius, Chord, Aerofoil, Axial Flow Induction Factor, Inflow Factor, Actuator Disc Concept, Momentum Theory

\section{Introduction}

Wind turbine generators are producing power by exchanging momentum with air particles in motion. While harnessing wind energy, wind turbine does not damage environment and is a clean source of energy. As per

\footnotetext{
"Corresponding author.
}

How to cite this paper: Agravat, S.M., Manyam, N.V.S., Mankar, S. and Harinarayana, T. (2015) Theoretical Study of Wind Turbine Model with a New Concept on Swept Area. Energy and Power Engineering, 7, 127-134. 
CEA 2013 report, 8\% of the installed power plant capacity is to be attributed to the wind energy installation. This only contributes $1.6 \%$ of total electricity generation [1]. Percentage share of wind energy as part of renewable energy installations in India is close to 70\%. Moreover, the PLF observed for different sites are reported to be in the range of $15 \%-30 \%$ [2].

Wind turbines are selected based on operating conditions of site. In other words, wind turbines are designed to provide maximum power for maximum occurring wind speed for which rotor and turbine are optimized and tested for. Like any other renewable energy sources, wind energy also has different intensity during different parts of the day and also for different months. With decline in wind energy, output decreases, below cut-off wind speed, output reduces proportionately till cut-in wind speed and thereafter no generation can be found. This is because at this instance momentum of wind particle is insufficient to rotate wind turbine and hence generator. The power output is proportional to the swept area of the blade and also to the pitch angle. During field conditions, momentum and RPM of turbine are adjusted to provide optimum torque and rpm. Traditionally, this is done by varying pitch angle and variable speed wind-turbine [3] [4]. As an alternate to this practice, wind farm need to be planned optimally, so as to take into account different types of wind characteristics [5].

There are number of methods reported in literature on design optimization of wind mill [6]-[13]. As per Muljadi, E. et al. [14] limit output power by suitable control limit in high wind speed regime and similarly try to extract more power by modifying pitch and speed of turbine to provide more torque from aerodynamic power. However, in all the cases, momentum of the blade causes loss of captured power. Talavera Juan, A. et al. [15] reported dynamic pair of overlapping blade segments used to control swept band area. M/s. Powersail ${ }^{\circledR}$ is in the development of adjustable swept area wind turbine model [16]. The company claims to increase the output by two-fold for an increase in swept area by 25\%. No technical study of their proprietary technology is reported. Mark Dawson et al. [17] of Energy Unlimited Inc. made first practical effort to overcome this limitation by changing swept area of rotor by adjusting the length of the blade. In his design Mark increased the length of the blade during low wind area and blade length is reduced during high wind area. US granted patent on June 7, 2005 vide US patent No. 6902370 B2 for variable speed wind turbine blade. In his design, Mark Dawson built $11 \mathrm{~m}$ long blade and a controller to change the blade length. Mark reported that the new design is beneficial for about 6000 hours in a year when the wind speed is lower than required. Except few efforts as reported below, not much R\&D work has been reported in literature or patent search based on the variable swept area wind mill as an effective tool to enhance power output. Moreover, the proprietary/patented technologies referred above are also only increasing the length of the blade. This way, aerodynamic shape is distorted. Our new design proposes to increase or decrease swept area so as to retain aerodynamic shape of the blade at all the time and thus extract more output.

\section{Materials and Methods}

To prove the new concept, new simulation is carried out using Q-Blade, V 8.0 software. This is open software developed by Hermann Fottinger Institute of Technical University (TU), Berlin. The software helps to evaluate the wind turbine blade profile on the basis of Blade Element Momentum theory. The main advantage with Blade Element Momentum theory is that it takes less time compared to that of Computational Fluid Dynamic analysis. Because of this advantage, a rapid evaluation of various blade designs is possible. The software helps user instantly to design the custom aerofoil and compute the performance polar and also has the capability to directly include the new design into rotor and simulate the power output of the wind generator. The software has necessary functions to simulate blades for HAWT and VAWT as well. NREL wind turbine model that is available in software library has been taken as reference blade design for further modifications. The blade profile that exist in Q-Blade V 8.0 trial version for NREL-5MW are provided in Table 1.

The first column indicates normal profile of original blade with $63 \mathrm{~m}$ radius, used as reference profile. Subsequent columns indicate the blade profile modified for its radius with radius of $70 \mathrm{~m}$, modified blade profile of $63 \mathrm{~m}$ blade with increased chord, $71.5 \mathrm{~m}$ blade profile with increased chord from tip to root in five sectors respectively. Increase in radius of reference blade was restricted to $71.5 \mathrm{~m}$, in order not to exceed the critical radius that defines the fatigue strength of the blade. The Blade profile diagrams are shown in Figure 1.

As per Actuator Disc concept, analysis of the aerodynamic behavior of wind turbines can be done without any specific turbine design but through Energy Extraction Process. In Figure 2, the energy extraction process through Actual Disc concept is shown. Upstream of the disc the stream-tube has a cross-sectional area smaller than 
Table 1. NREL-5MW reference blade profile with modified blade profiles for simulation**

\begin{tabular}{|c|c|c|c|c|c|c|c|}
\hline \multicolumn{2}{|c|}{ Normal } & \multicolumn{2}{|c|}{ Increased radius } & \multicolumn{2}{|c|}{ Increased chord } & \multicolumn{2}{|c|}{ Increased radius \& chord } \\
\hline Length & Chord & Length & Chord & Length & Chord & Length & Chord \\
\hline 0.00 & 3.20 & 0.00 & 3.20 & 0.00 & 3.20 & 0.00 & 3.20 \\
\hline 1.36 & 3.54 & 1.36 & 3.54 & 1.36 & 3.54 & 1.36 & 3.54 \\
\hline 4.10 & 3.85 & 4.10 & 3.85 & 4.10 & 3.85 & 4.10 & 3.85 \\
\hline 6.83 & 4.17 & 6.83 & 4.17 & 6.83 & 4.17 & 6.83 & 4.17 \\
\hline 10.25 & 4.55 & 10.25 & 4.55 & 10.25 & 4.55 & 10.25 & 4.55 \\
\hline 14.35 & 4.65 & 14.35 & 4.65 & 14.35 & 4.65 & 14.35 & 4.65 \\
\hline 18.45 & 4.46 & 18.45 & 4.46 & 18.45 & 4.46 & 18.45 & 4.46 \\
\hline 22.55 & 4.25 & 22.55 & 4.25 & 22.55 & 4.25 & 22.55 & 4.25 \\
\hline 26.65 & 4.01 & 26.65 & 4.01 & 26.65 & 4.01 & 26.65 & 4.01 \\
\hline 30.75 & 3.75 & 30.75 & 3.75 & 30.75 & 3.75 & 30.75 & 3.75 \\
\hline 34.85 & 3.50 & 34.85 & 3.50 & 34.85 & 3.50 & 34.85 & 3.50 \\
\hline 38.95 & 3.26 & 38.95 & 3.26 & 38.95 & 3.26 & 38.95 & 3.26 \\
\hline 43.05 & 3.01 & 43.05 & 3.01 & 43.05 & 3.01 & 43.05 & 3.01 \\
\hline 47.15 & 2.76 & 47.15 & 2.76 & 47.15 & 2.76 & 47.15 & 2.76 \\
\hline 51.25 & 2.52 & 51.25 & 2.52 & 51.25 & 4.55 & 51.25 & 4.55 \\
\hline 54.67 & 2.31 & 54.67 & 2.31 & 54.67 & 4.17 & 54.67 & 4.17 \\
\hline 57.40 & 2.09 & 57.40 & 2.09 & 57.40 & 3.85 & 57.40 & 3.85 \\
\hline 60.13 & 1.40 & 60.13 & 1.40 & 60.13 & 3.54 & 60.13 & 3.54 \\
\hline 61.50 & 0.70 & 70.00 & 0.70 & 61.50 & 3.20 & 70.00 & 3.20 \\
\hline
\end{tabular}

*All dimensions are in meter.

that of the disc and an area larger than the disc downstream. The expansion of the stream-tube is because the mass flow rate must be the same everywhere. The mass of air which passes through a given cross section of the stream-tube in a unit length of time is $\rho A U$, where $\rho$ is the air density, $A$ is the cross-sectional area and $U$ is the flow velocity. The mass flow rate must be the same everywhere along the stream tube and so

$$
\rho A_{\infty} U_{\infty}=\rho A_{d} U_{d}=\rho A_{w} U_{w}
$$

The symbol $\infty$ refers to conditions far upstream, $d$ refers to conditions at the disc and $w$ refers to conditions in the far wake.

The wind energy after actuator disc is given by,

$$
U_{w}=(1-2 a) U_{\infty}
$$

It is usual to consider that the actuator disc induces a velocity variation which must be superimposed on the free-stream velocity. The stream-wise component of this induced flow at the disc is given by $-a U_{\infty}$, where " $a$ " is called the axial flow induction factor, or the inflow factor. At the disc, therefore, the net stream-wise velocity is

$$
U_{d}=U_{\infty}(1-a)
$$

Following the momentum theory using the Bernoulli's principle applied to the upstream and downstream sections of the stream tube, separate equations are calculated for energy upstream and downstream as the total 


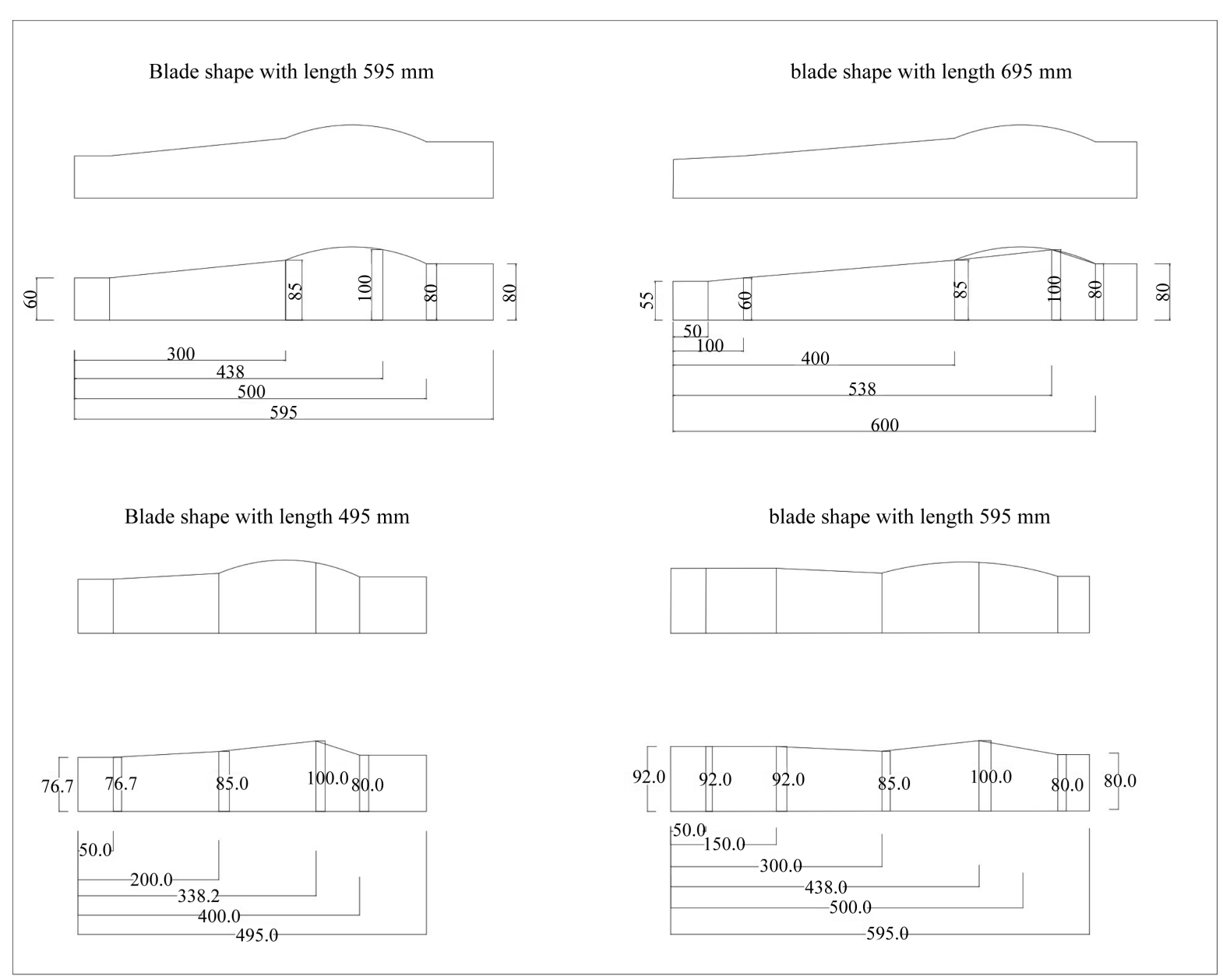

Figure 1. Blade profile diagrams.

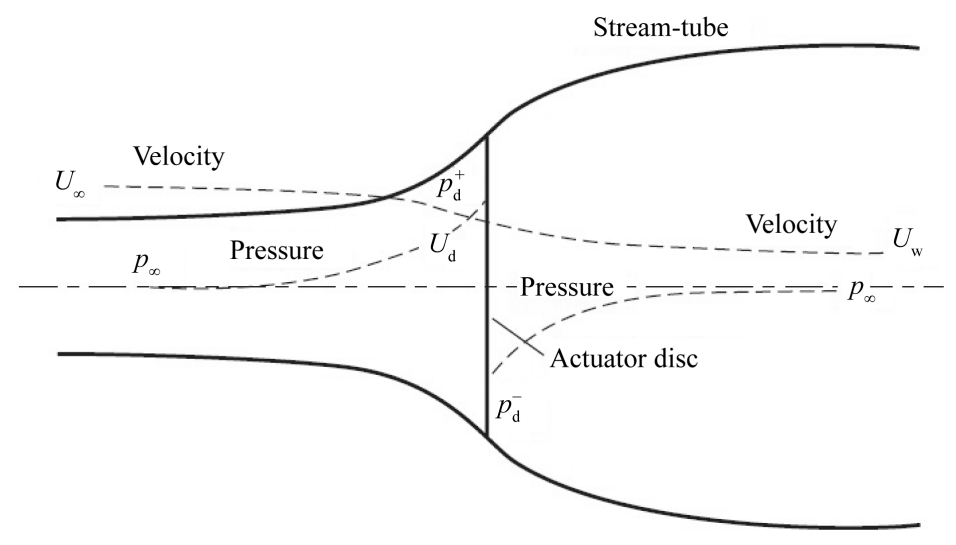

Figure 2. An energy extracting actuator disc and stream tube.

energy is different for both the streams. From further calculations we derive Equation (1).

Using Equations (1) \& (3), we obtain

$$
\left(P_{d}^{+}-P_{d}^{-}\right)=\left(U_{\infty}-U_{w}\right) \rho A_{d} U_{\infty}(1-a)
$$

As this force is concentrated at the actuator disc the rate of work done by the force is $F U_{d}$ and hence the power extraction from the air is given by 


$$
\text { Power }=F U_{d}=2 \rho A_{d} U_{\infty}^{3} a(1-a)^{2}
$$

The power coefficient is defined as

$$
C_{p}=\frac{\text { power }}{\frac{1}{2} \rho U_{\infty}^{3} A_{d}}
$$

$C_{p}$ will be max when

$$
\begin{gathered}
\frac{\mathrm{d} C_{p}}{\mathrm{~d} a}=0 \\
\therefore 4(1-a)(1-3 a)=0 \\
a=\frac{1}{3} \\
\therefore C_{p \max }=\frac{16}{27}=0.593
\end{gathered}
$$

The coefficient of power $\left(C_{p}\right)$ is then used to calculate power output.

\section{Results \& Discussion}

The percentage increase in power output for different radius (s) in steps of $2 \mathrm{~m}$ from $63 \mathrm{~m}$ radius as reference blade are simulated against power output and summarized in Table 2. Figure 3 graphically summarizes the simulation result given in Table 2. The right extreme column in Table 2 indicates percentage gain for 71.5 m radius blade over reference radius.

Similarly, percentage gain in output power delivered according to the chord variations is summarized in Table 3.

Figure 4 summarizes change in power output for variation in chord of the blade proportion to the radius and also for varying the chord alone.

A graph demonstrating measurements, taken by Mark Dawson et al., for extended length (only), wind blade design is reproduced here in Figure 5 for comparison.

Table 2. Simulation result for power output for variation in radius*.

\begin{tabular}{ccccccc}
\hline Wind speed & Existing radius-63 $\mathbf{m}$ & Radius-64.5 $\mathbf{~ m}$ & Radius-66.5 $\mathbf{~ m}$ & Radius $\mathbf{6 8 . 5} \mathbf{~ m}$ & Radius-71.5 $\mathbf{~ m}$ & Benefit over existing \\
\hline 3 & 1.0 & 1.1 & 1.2 & 1.2 & 1.3 & 25.42892 \\
4 & 3.8 & 4.2 & 4.4 & 4.4 & 4.8 & 26.60006 \\
5 & 8.5 & 9.5 & 10.0 & 10.0 & 10.8 & 26.94602 \\
6 & 15.5 & 17.5 & 18.4 & 18.4 & 19.8 & 27.21183 \\
7 & 24.9 & 27.8 & 29.1 & 29.1 & 31.2 & 25.19004 \\
8 & 37.2 & 41.3 & 44.1 & 44.1 & 47.2 & 27.05546 \\
9 & 52.9 & 59.3 & 62.7 & 62.7 & 66.6 & 25.87414 \\
10 & 72.4 & 80.3 & 84.1 & 84.1 & 90.1 & 24.45874 \\
11 & 95.9 & 100.0 & 100.0 & 100.0 & 100.0 & 4.30885 \\
12 & 100.0 & 100.0 & 100.0 & 100.0 & 100.0 & 0 \\
13 & 100.0 & 100.0 & 100.0 & 100.0 & 100.0 & 0 \\
14 & 100.0 & 100.0 & 100.0 & 100.0 & 100.0 & 0
\end{tabular}

${ }^{*}$ All values are in percentage (\%) of simulated output against output for reference turbine at rated capacity. 


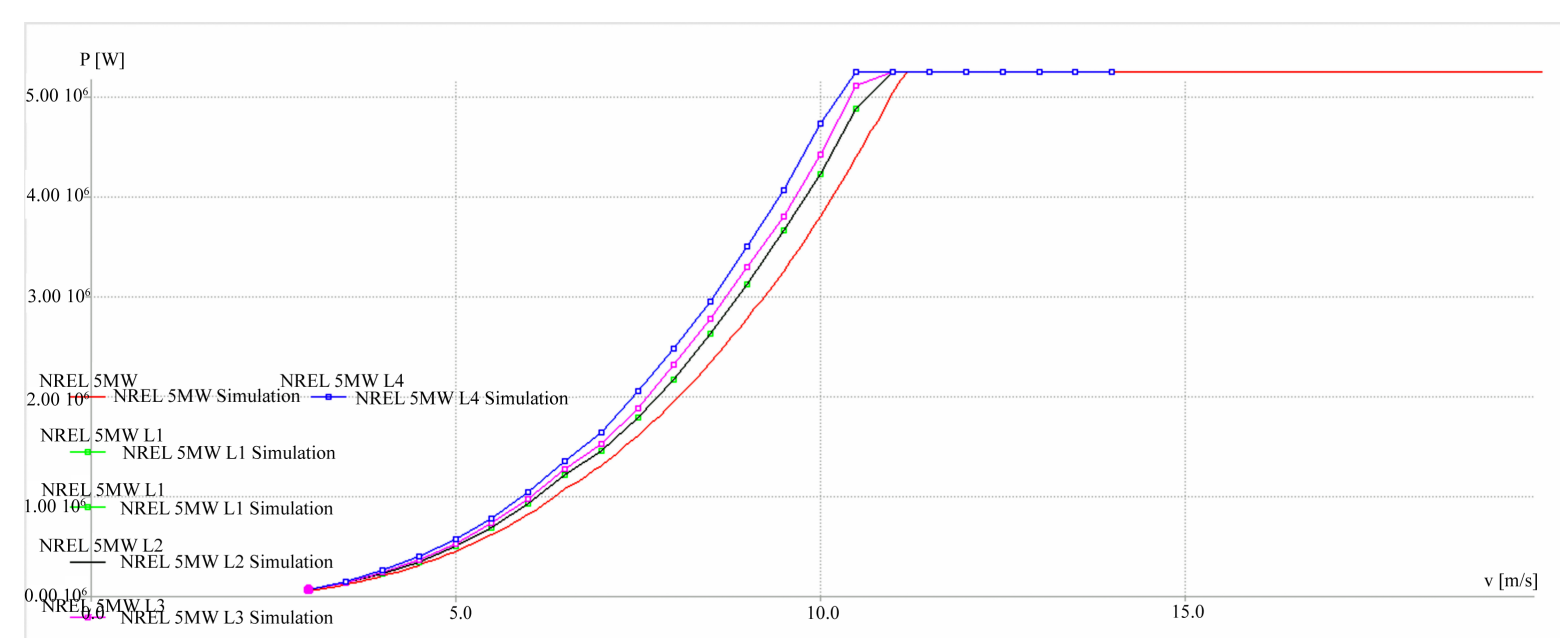

Figure 3. Graphical summary of simulation for variation in radius.

Table 3. Simulation result for power output for variation in radius \& chord simultaneously and variation in chord alone*

\begin{tabular}{ccc}
\hline Wind speed & $\begin{array}{c}\text { Radius \& Chord-63 m \& from tip to root by } \\
\mathbf{2 1 \%} \text { proportionately till five steps }\end{array}$ & $\begin{array}{c}\text { Chord-from tip to root by 21\% proportionately } \\
\text { till five steps }\end{array}$ \\
\hline 3 & 0.0 & 0.1 \\
4 & 3.3 & 2.9 \\
5 & 9.3 & 0.8 \\
6 & 18.4 & 14.9 \\
7 & 30.6 & 24.4 \\
8 & 45.7 & 36.6 \\
9 & 46.2 & 52.2 \\
10 & 89.8 & 71.7 \\
11 & 100.0 & 95.6 \\
12 & 100.0 & 100.0 \\
13 & 100.0 & 100.0 \\
14 & 100.0 & 100.0 \\
\hline
\end{tabular}

*All values are in percentage (\%) of simulated output against output for reference turbine at rated capacity.

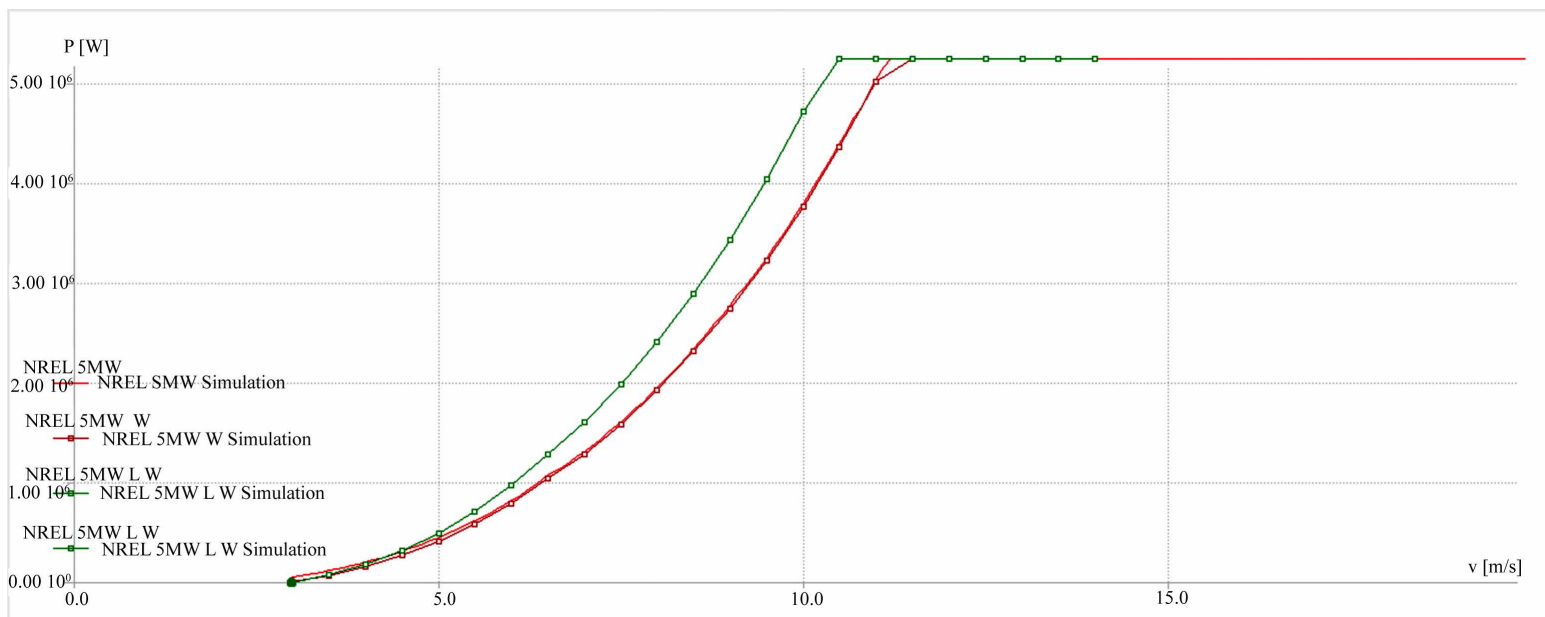

Figure 4. Summarizes change in power output for variation in chord of the blade proportion to the radius and also for varying the chord alone. 


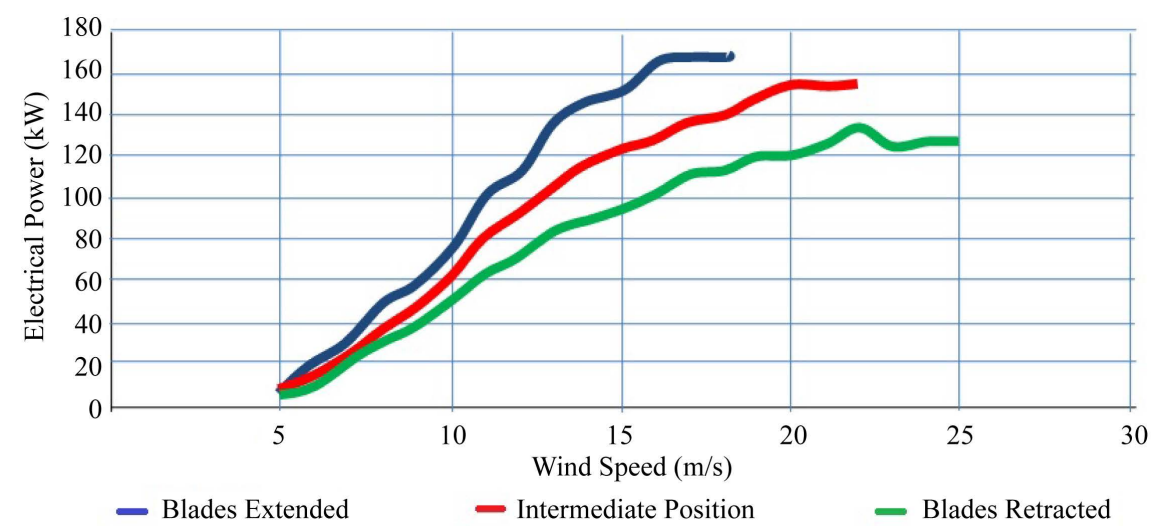

Figure 5. Reproduced experimental, proof-of-concept power curve for variable length wind turbine by Mark H. Dawson et al. [17].

In Figure 3, the right extreme line (red color) represents the power curve related to actual rotor. The curves to the left represent power curves with increased radius of rotor in various orders. In all the cases, output delivered by modified blade dimensions is found to be greater than the output received w.r.t. reference blade. The left extreme power curve (violet color) in Figure 3 indicates the power output for $71.5 \mathrm{~m}$. It is evident from the simulation result that increase in radius is favored at all the wind velocity including cut-in wind speed.

The right extreme line (red color) in Figure 4 shows two curves exactly coinciding with each other. The only difference observed is for the wind speed corresponding to rated wind speed. It can be seen that no significant increase in power output observed except close to rated wind-speed that elevates the rated wind velocity value. The left extreme line (green color) in Figure 4 demonstrates the power curve correspond to simultaneous \& proportionate increase in tip chord and radius of the blade. The curve rises at all the wind speed over power curve corresponding to reference blade. It yields more output at higher wind speed, reaches the maximum power earlier than the existing and hence, increases the utilization of the wind generator CUF.

The simulation results confirm significant gain in power output corresponding to the increase in radius of the rotor alone. Maximum gain of $27 \%$ is observed for radius equivalent to the critical radius i.e. $71.5 \mathrm{~m}$ compared to the radius of reference rotor i.e. $63 \mathrm{~m}$. There is no gain observed for increase in the chord of the blade alone.

Best results are obtained when both chord and radius both are increased simultaneously. It can be inferred that the wind turbine shown promising results for the output power generated at both the lower and higher wind speed. Major impact observed in the generator reaches the synchronous speed at an earlier (i.e., at lower than the rated wind speed) stage than the existing.

\section{Conclusions}

Output of the wind turbine increases with increase in chord radius (length of blade) at all wind velocities; the power output becomes maximum at rated wind velocity. Thereafter output is stable for any wind velocity up to cut-off wind velocity. Higher gains can be obtained with more increase in blade length from lower to higher wind speed. It is possible to achieve state of rated power output at comparatively lower wind velocity than the rated wind velocity by increasing swept area. That means, more power can be harnessed on yearly basis. We can logically conclude that reduction in swept area can also generate power from wind mill above cut-off wind velocities wherein otherwise wind mill will stop for safety. Trend in both the cases matches well with each other.

Additional gain can be obtained by increasing width also proportionately which is not experimented before. It can be concluded that in order to gain more output from wind turbine, complete aerodynamic shape should be changed. We recommend that experiments need to be conducted on the basis of these simulation studies to identify the percentage gain and also to identify practical constraints that can lower the gain.

\section{Acknowledgements}

Authors like to acknowledge management team of Gujarat Energy Research \& Management Institute (GERMI), Gandhinagar for providing all necessary support to conduct present study. Special acknowledgements to Vice 
Chairman \& Managing Trusty (VGMT)—GERMI and Managing Director of M/s. Gujarat State Petroleum Corporation (GSPC), Gandhinagar for providing necessary funding under Summer Internship Project (SIP) scheme.

\section{References}

[1] CEA Report (2013) http://cea.nic.in/reports/yearly/annual_rep/2012-13/ar_12_13.pdf

[2] Madhu, S. et al. (2014) A Review of Wind Energy Scenario in India. International Journal of Environmental Sciences, 3, 87-92.

[3] Sing, C. (2012) Variable Speed Wind Turbine. International Journal of Engineering Science, 2, 652-656.

[4] Li, H. and Chen, Z. (2009) Design Optimization and Site Matching of Direct-Drive Permanent Magnet Wind Power Generator Systems. Renew. Energy, 34, 1174-1185. http://dx.doi.org/10.1016/j.renene.2008.04.041

[5] Eminoglu, U. and Ayasun, S. (2014) Modeling and Design Optimization of Variable-Speed Wind Turbine Systems. Energies, 7, 402-419. http://dx.doi.org/10.3390/en7010402

[6] Fingersh, L., Hand, M. and Laxson, A. (2006) Wind Turbine Design Cost and Scaling Model; Technical Report NREL/TP-500-40566. National Renewable Energy Laboratory (NREL), Golden.

[7] Diveux, T., Sebastian, P., Bernard, D., Puiggali, R.J. and Grandidier, J.Y. (2001) Horizontal Axis Wind Turbine Systems: Optimization Using Genetic Algorithms. Wind Energy, 4, 151-171. http://dx.doi.org/10.1002/we.51

[8] Fuglsang, P., Bak, C., Schepers, J.G., Bulder, B., Olesen, A., van Rossen, R. and Cockerill, T. (2010) Site Specific Design Optimization of Wind Turbines; Technical Report JOR3-CT98-0273. National Laboratory Risø, Roskilde.

[9] Collecutt, G.R. and Flay, R.G. (1996) The Economic Optimization of Horizontal Axis Wind Turbine Design Parameters. Journal of Wind Engineering and Industrial Aerodynamics, 61, 87-97. http://dx.doi.org/10.1016/0167-6105(96)00048-7

[10] Fuglsang, P. and Bak, C. (2002) Site-Specific Design Optimization of Wind Turbines. Wind Energy, 5, 261-279. http://dx.doi.org/10.1002/we.61

[11] Kongam, C. and Nuchprayoon, S. (2010) A Particle Swarm Optimization for Wind Energy Control Problem. Renewable Energy, 35, 2431-2438. http://dx.doi.org/10.1016/j.renene.2010.02.020

[12] Fuglsang, P. and Madsen, H.A. (1999) Optimization Method for Wind Turbine Rotors. Journal of Wind Engineering and Industrial Aerodynamics, 80, 191-206. http://dx.doi.org/10.1016/S0167-6105(98)00191-3

[13] Maki, K., Sbragio, R. and Vlahopoulos, N. (2012) System Design of a Wind Turbine Using a Multi-Level Optimization Approach. Renewable Energy, 43, 101-110. http://dx.doi.org/10.1016/j.renene.2011.11.027

[14] Muljadi, E. and Butterfield, C.P. (1999) Pitch-Controlled Variable-Speed Wind Turbine Generation. IEEE Transactions on Industry Applications, 37, 240-246.

[15] Talavera Juan, A. and Cassarrubios Francisco, J. (2005) Swept Area Regulation for Increased Energy Output in Off-Shore Wind Turbine. http://wind.nrel.gov/public/SeaCon/Proceedings/Copenhagen.Offshore.Wind.2005/documents/papers/Poster/J.A.Talav era_SweptAreaRegulationforIncreasedEnergy.pdf

[16] http://www.powersails.com/powersails/adjustable-swept-area-asa/

[17] Dawson Mark, H. (2006) Variable Length Wind Turbine Blade. Project Report. 